\title{
Production of Monoclonal Antibody to Subtype 9 of Neisseria meningitidis and the Distribution of this Subtype in Brazil
}

\author{
Elza F.T. Belo, Ligia M.C.C. Coutinho, \\ Aline S. Ferraz and Elizabeth N. De Gaspari
}

\author{
Adolfo Lutz Institute, São Paulo/SP, Brazil
}

\begin{abstract}
A new monoclonal antibody (5F81A4P1.9), which is specific for subtype 9 antigen of meningococci, was studied. The antibodies were raised against a previously non-typable (NT) serogroup B strain from Brazilian patients and were found to react with the subtype antigen of prototype reference strains for subtype 9 (M982), as well as with those of homologous strains. The subtype 9 epitope was found in $6.8 \%$ of serogroup B strains among 602 strains of Neisseria meningitidis case isolates, including representative isolates from Brazilian states. Subtype P1.9 was predominantly related to serogroup B in Brazil among the isolates collected during the $N$. meningitidis epidemic in 1992. No significant differences were observed in the occurrence of subtype P1.9 among strains isolated from several Brazilian states. Fluorescence-activated cellsorter analysis showed that 5F81A4 MAb recognized a $46 \mathrm{kDa}$ protein on the surface of a homologous strain of $N$. meningitidis (B:4:P1.9). These results, in association with a bactericidal activity assay for $5 \mathrm{F81} \mathrm{A4}$, and with experimental passive protection in mice, demonstrated the importance of subtype 9 class 1 proteins of $N$ meningitidis in Brazil. Serotyping is essential for the development of vaccination strategies.

Key Words: Neisseria meningitidis, monoclonal antibodies, Brazilian meningococcus strains, serotyping, subtyping.
\end{abstract}

Neisseria meningitidis is an encapsulated bacteria that has been the cause of severe diseases, both in developing countries and the western world. Infection with encapsulated bacteria can be circumvented by immunization with type-specific polysaccharide-protein conjugated vaccines generating antibodies to the capsular polysaccharides. The polysaccharide from serogroup B meningococci, a polymer of alfa-2,8neuraminic acid, is a common epitope that is also found on the surface of human cells. For this reason, many investigators have chosen it to develop outer membrane protein-based vaccines against meningococci [1].

Received on 14 July 2004; revised 20 October 2004.

Address for correspondence: Dr. Dr. Elizabeth N De Gaspari. Instituto Adolfo Lutz.355,11 andar, Zipcode:01246-902, São Paulo, Brazil. Phone (55) (11) 3068-28-98. Fax: (55) (11) 308535-05.E-mail : egaspari@ial.sp.gov.br

The Brazilian Journal of Infectious Diseases 2004;8(6):407-418 (C) 2004 by The Brazilian Journal of Infectious Diseases and Contexto Publishing. All rights reserved.
Since 1988, large epidemics of meningococcal disease (MD) due to meningococcus B disease (MenB) have been occurring in the greater São Paulo city (GSP) region, in the state of São Paulo [2].

The outer membrane proteins of $N$. meningitidis have attracted attention mainly for two reasons; their use for the classification of meningococcal isolates into serotypes and subtypes, and as potential components of vaccines against this pathogen. Meningococci reveal higher genetic diversity than the most other human pathogenic bacteria. This can be partly explained by horizontal intraspecies recombination and incorporation from closely related Neisseria species [3]. Traditionally, strains have been characterized by antibodies that recognize the surface-exposed epitopes on the capsule or the outer membrane. By means of this technique, 13 serogroups (identifying capsule antigens), 20 serotypes (identifying class 2/3 OMP antigens), and 20 subtypes (identifying class 1 OMP antigens) have been defined [4]. An example of serological 
typing nomenclature is $\mathrm{B}: 4: \mathrm{P} 1.9$, indicating that it is meningococci serogroup B, serotype 4, and subtype P1.9. Based on the antigenic properties of this lipopolysaccharide, renamed lipooligosaccharide (LOS) because of its relatively short sugarchain, another 13 immunotypes, designated by the letter L, can be distinguished [5]. Additional typing is achievable by using antigenic properties of immunoglobulin A1 (IgA1) proteases and $N$. meningitidis pili [6].

Epidemiological studies of MD were not possible prior to the development of methods for serogroup identification of strains [7]. Serotyping has enabled precise studies on the prevalence of serogroup B and $\mathrm{C}$ strains as sources of infection. This method has been used to assess strains isolated from meningococcal meningitis outbreaks, and to compare the serotype strains isolated from patients and carriers.

Until recently, hyperimmune sera were used to type bacterial antigens; however, obtaining high-grade antisera was difficult, and typing was time-consuming, as an extensive serum absorption procedure was required, and elucidation of numerous cross-reactions was necessary [8]. The advent of monoclonal antibodies (Mabs) has eliminated many technically problematic issues, and it has greatly improved the accuracy and reproducibility of meningococcal serotyping procedures. Nevertheless, some types and serotypes are still identified by means of polyclonal rabbit sera, due to a lack of corresponding MAbs.

We characterized a monoclonal antibody to the class 1 outer membrane protein of $N$. meningitidis subtype 9, and we examined the distribution of this subtype epitope among Brazilian meningococcal strains. (Parts of this work were presented at the Tenth International Pathogenic Neisseria Conference, Winchester, England [9]. Whole cell suspensions of 602 case strains of $N$. meningitidis from Brazil included 427 strains from different subtypes, and 175 (NT) strains previously analyzed with P1.9 monoclonal antibody. The group B strains were isolated in 1992 from patients with meningococcal disease, which were screened on dot blots with a panel of serotypes and MAb subtypes, as described elsewhere [10].

\section{Material and Methods}

\section{Growth and maintenance of bacterial strains}

The N. meningitidis serogroup B strain used for $\mathrm{MAb}$ production was isolated from an MD epidemic that occurred in 1992 in GSP (case strain), and it was initially classified as serotype 4 and subtype NT (N368/ 88). Reference and case strains of $N$. meningitidis: 120M, 7880, 7889, 44/89, 1002/90, 337/90, 735/ 90, M981, M1027, M992, M978, M982, M136, 1080, B16B6, 2996, S3446, H355, H44/76, 60E, 6557, M990, 190I were used (Table 1). The new monoclonal antibody meningococcal strains were maintained at $-70^{\circ} \mathrm{C}$ in skim milk or were lyophilized and stored at $4^{\circ} \mathrm{C}$. N. meningitidis strains were grown on Tryptic Soy Agar (TSA) (Difco Laboratories, Detroit, MI) plates supplemented with $1 \%$ horse serum in a $5 \% \mathrm{CO}_{2}$ atmosphere for 16 to $18 \mathrm{~h}$ at $37^{\circ} \mathrm{C}$ in a candle extinction jar. All of the meningococci were isolated from blood or cerebrospinal fluid specimens from patients with systemic disease, and the bacteria were deposited in the culture collection of the Adolfo Lutz Institute, São Paulo, SP, Brazil. Following biochemical characterization, the strains were serogrouped at the Bacteriology Section of Adolfo Lutz Institute by the slide agglutination technique, using antisera produced against nine major capsular serogroups. These antisera were prepared by the National Reference Center for Meningitis (Adolfo Lutz Institute). The bacteria used in this study were serosubtyped by dot-blotting, using Mabs.

\section{Monoclonal antibody production and characterization}

Production of MAb was made using a previously described technique [11]. Briefly, BALB/c mice were immunized with a saline suspension of $N$. meningitidis $368 / 88$, containing approximately $10^{8}$ bacteria that had been heat-inactivated at $56^{\circ} \mathrm{C}$ for $30 \mathrm{~min}$. Mice were immunized with 4 doses of meningococci suspension, both intraperitonealy and intravenously, 3 days before fusion. Spleens wereharvested 3 days after the final immunization, and lymphocytes were fused with 
P3X63-Ag 8.653 mouse myeloma cells at a ratioof 4:1, as previously described. Positive clones were selected by enzyme-linked immunosorbent assay (ELISA) using plates coated with 368/88 outer membrane complex (OMC). Western blot analysis was performed to confirm the binding of the MAb to class $1 \mathrm{OMP}(46 \mathrm{kDa})$ of the $368 / 88$ strain. Ascites fluids were produced by means injection of $5 \times 10^{6}$ hybridoma cells into pristane-primed BALB/c mice. Ascites fluids were pooled, the titers were determined, and they were then stored at $-20^{\circ} \mathrm{C}$ in aliquots. All procedures with animals were in accordance with the principles of the Brazilian Code for the Use of Laboratory Animals. The MAbs class and subclass were determined by ELISA, using peroxidase-conjugated anti-mouse immunoglobulin following the manufacturer's (mouse hybridoma subtyping kit; Boehringer Mannheim Biochemicals, Indianapolis) instructions.

\section{Dot blot analysis}

The cell suspension ( $1 \mu \mathrm{L}$ of bacteria) was suspended in PBS, pH 7.4, with $0.02 \%$ sodium azide. Cells were heat-inactivated at $56^{\circ} \mathrm{C}$ for $30 \mathrm{~min}$ and the absorbance of the suspension was adjusted to OD 0.1 at $650 \mathrm{~nm}$ using a Coleman $6^{\mathrm{A}}$ Junior Spectrophotometer. The bacteria were dotted onto nitrocellulose membranes, and the membranes were dried for $10 \mathrm{~min}$ at room temperature (RT) and used immediately. Membranes were blocked for 30 min with 5\% skim milk (Nestle, Brazil). MAbs of various specificities, diluted to 1:10,000 in blocking buffer, were added. Membranes were incubated overnight at RT on a rotator, and then washed three times with PBS. The membranes were placed in a solution containing $1 \mu \mathrm{g} / \mathrm{mL}$ of phosphataselabeled goat anti-mouse immunoglobulin $\mathrm{G}(\mathrm{IgG})$ plus IgM (Kirkegaard \& Perry Laboratories, Inc., Gaithersburg, MD) diluted in blocking buffer, and allowed to react for $2 \mathrm{~h}$ at RT on a rotator. The membranes were washed three times with PBS, and one time with $50 \mathrm{mM}$ Tris ( $\mathrm{pH} \mathrm{8.0)}$ and developed adding $1 \mathrm{mg}$ of naphthol AS-MX phosphate per $\mathrm{mL}$ plus $2 \mathrm{mg}$ of Fast Red TR saltper $\mathrm{mL}$ in $50 \mathrm{mM}$ Tris buffer (pH 8.0) (Sigma Chemical Co., St. Louis, Mo).

\section{Preparation of OMC of $N$. meningitidis}

The OMC was prepared from $N$. meningitidis Brazilian epidemic strain N368/88. Whole cells were suspended in lithium acetate buffer $\mathrm{pH}$ 6.0, containing $20 \mathrm{mM}$ sodium chloride and $10 \mathrm{mM}$ sodium EDTA, and then were shaken with 6-mm glass beads at 300 rpm for $2 \mathrm{~h}$. The supernatant was collected and centrifuged at 40,000 $\mathrm{g}$ for $2 \mathrm{~h}$. The pellet was washed three times, and then suspended in distilled water. Each preparation was diluted to a final concentration of $1 \mathrm{mg}$ protein per $\mathrm{mL}$ and stored at $-70^{\circ} \mathrm{C}$ in aliquots. Protein concentrations of OMC were determined by the Lowry technique [12].

\section{SDS-PAGE and immunoblotting}

SDS-PAGE was carried out in $13 \%$ acrylamide gels measuring $16 \times 16 \times 0.15 \mathrm{~cm}$. OMC at a concentration of $2.5 \mathrm{mg}$ of protein per $\mathrm{mL}$ and lowmolecular-weight protein standards (Amersham \& Biociences) were mixed 1:1 with treatment buffer (0.125 M Tris-Cl (pH 6.8) , 4\% SDS, 20\% glycerol, $10 \%$ 2-mercaptoethanol)and boiled for $10 \mathrm{~min}$ before being loaded onto the gels. Gels were run at a constant current of $30 \mathrm{~mA}$ per gel at $10^{\circ} \mathrm{C}$ for approximately $4 \mathrm{~h}$. The gels were then stained with Coomassie brilliant blue R-250 or blotted onto nitrocellulose filters (0.22$\mu \mathrm{m}$ pore size) BioRad at $30 \mathrm{~V}$ overnight at $10^{\circ} \mathrm{C}$. Immunoblotting was performed as described for dot blotting, except for the primary antibody, which was diluted 1:2000.

\section{Bactericidal activity}

The bactericidal assay was carried out using Brazilian epidemic serogroup B N homologous strain 368/88 in 96-well plates, as described by De Gaspari and Zollinger[13], with some modifications. Briefly, the final reaction mixture $(50 \mu \mathrm{L})$ contained $25 \mu \mathrm{L}$ of serial twofold dilutions of test serum that had been heatinactivated at $56^{\circ} \mathrm{C}$ for $30 \mathrm{~min}, 12.5 \mu \mathrm{L}$ baby rabbit serum as the complement source, screened for absence of anti-meningococcal activity, and $12.5 \mu \mathrm{L}$ of a 
Table 1. Reference and case strains of Neisseria meningitidis used in Dot ELISA for typing using the monoclonal 5F81A4

\begin{tabular}{lccc}
\hline Strains & Serogroup & Serotype & Subtype \\
\hline $120 \mathrm{M}$ & $\mathrm{A}$ & $\mathrm{NT}$ & $\mathrm{NT}$ \\
7880 & $\mathrm{~A}$ & $\mathrm{NT}$ & $\mathrm{P} 1.3$ \\
7889 & $\mathrm{~A}$ & 4 & $\mathrm{NT}$ \\
$44 / 89$ & $\mathrm{~B}$ & 4 & $\mathrm{P} 1.15$ \\
$1002 / 90$ & $\mathrm{C}$ & $2 \mathrm{~b}$ & $\mathrm{P} 1.3,6$ \\
$337 / 90$ & $\mathrm{~B}$ & 9 & $\mathrm{P} 1.14$ \\
$735 / 90$ & $\mathrm{~B}$ & 8 & $\mathrm{P} 1.6$ \\
M981 & $\mathrm{B}$ & 4 & $\mathrm{NT}$ \\
M1027 & $\mathrm{A}$ & 4 & 21 \\
M992 & $\mathrm{B}$ & 5 & $\mathrm{P} 1.1,7$ \\
M990 & $\mathrm{B}$ & 6 & $\mathrm{P} 1.6$ \\
M978 & $\mathrm{B}$ & 8 & $\mathrm{P} 1.1,7$ \\
M982 & $\mathrm{B}$ & 9 & $\mathrm{P} 1.9$ \\
M136 & $\mathrm{B}$ & 11 & $\mathrm{NT}$ \\
M1080 & $\mathrm{B}$ & 1 & $\mathrm{P} 1.1,7$ \\
B16B6 & $\mathrm{B}$ & $2 \mathrm{a}$ & $\mathrm{P} 1.2$ \\
2996 & $\mathrm{~B}$ & $2 \mathrm{~b}$ & $\mathrm{P} 1.2$ \\
S3446 & $\mathrm{B}$ & 14 & $\mathrm{P} 1.6$ \\
H355 & $\mathrm{B}$ & 15 & $\mathrm{P} 1.15$ \\
H44/76 & $\mathrm{B}$ & 15 & $\mathrm{P} 1.7,16$ \\
$60 \mathrm{E}$ & $\mathrm{C}$ & 16 & $\mathrm{P} 1.1,7$ \\
6557 & $\mathrm{~B}$ & 17 & $\mathrm{NT}$ \\
$190 \mathrm{I}$ & $\mathrm{B}$ & 18 & $\mathrm{P} 1.6$ \\
\hline
\end{tabular}

suspension of exponential-phase meningococci $(60 \mathrm{cfu}$ per well), grown in agar containing $1 \%(\mathrm{v} / \mathrm{v})$ horse serum. The reaction mixture was incubated at $37^{\circ} \mathrm{C}$ for $30 \mathrm{~min}$, and $130 \mu \mathrm{L}$ tryptic soy agar (TSA), cooled to approximately $45^{\circ} \mathrm{C}$, was added to each well. The mixture was allowed to solidify and the plates were incubated for $18 \mathrm{~h}$ at $37^{\circ} \mathrm{C}$ in $5 \% \mathrm{CO}_{2}$. Viable bacteria counts were done at time $0\left(t_{0}\right)$, before incubation with complement, in order to estimate the number of cfu for $100 \%$ survival, by plating $12.5 \mu \mathrm{L}$ bacterial stock suspension onto a 150 x $150 \mathrm{~mm}$ TSA plate. Control wells included on each microtiter plate contained: (i) bacteria, complement and buffer (complement- dependent control) or (ii) bacteria, heat-inactivated complement and buffer (complement-independent control). In addition, a positive control was included in each assay, consisting of serial dilutions of a known positive serum. Assays were carried out in duplicate [14]. The bactericidal titer of the serum was defined as the reciprocal of the serumdilution that killed $50 \%$ of the bacteria at $t_{0}$.

\section{Bacteremia}

A mouse model of infection [11] was used to determine the protective capacity of 5F81A4 MAb . 
Figure1: Dot-blot assay with whole cells of Neisseria meningitidis of Brazilian isolates serogroup B. Non typable strains 1a: culture supernatant monoclonal antibody P1.9 diluted 1:500; 1b: ascite monoclonal antibody P1.9 diluted 1:2,000; 2: immunoreactivity of ascite of monoclonal antibody P1.9 with reference strains M 982 (P1.9) and strains described in Table.1; 3: analysis of proteins in $N$. meningitidis outer membrane components preparations. 3a and 4c: molecular weight standards are indicated in kilodaltons; b: SDS-PAGE profiles after staining with Coomassie blue of OMC preparations of the strains N 368/88; 4a: immunoblot reactivity of $N$. meningitidis N 368/88; 4c: N 16/92; 4e: N17/92 case strains with the MAb 5F81A4, P1.9;4b: N368/88; 4d: N16/92, and 4f: N17/92 N. meningitidis case strains imunoreactivity with the new monoclonal antibody (1A11E10) against class $3(37 \mathrm{kDa})$ of $N$. meningitidis.

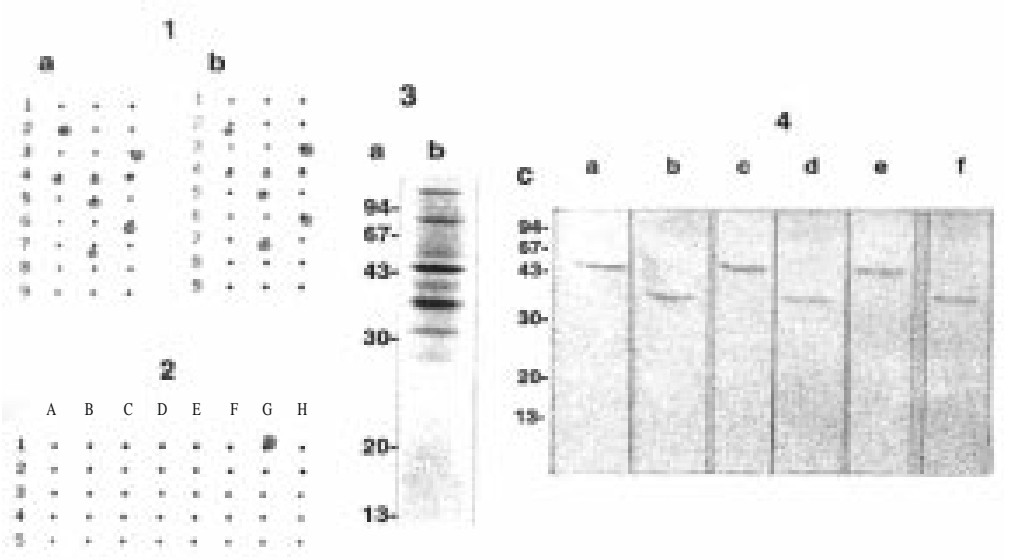

Figure 2. Level of bacteremia present in BALB/c mice after $0.25 \mathrm{~mL} 5 \mathrm{~F} 81 \mathrm{~A} 4$ hybridoma ascite fluid inoculation diluted in PBS. a: PBS as control; b: MAb 1:2,000; C: MAb 1:5,000; d: MAb 1:10,000, e: MAb 1:20,000 dilution. The bacteria B:4:P1.9 (homologous strain) $4 \times 10^{3}$ bacteria $/ \mathrm{mL}$ i.p. The level of bacteremia induced by the meningococcal strain was calculated from at least two separate experiments as the arithmetic mean CFU per $\mathrm{mL}$ of blood \pm the standard deviation. Each value represents a mean of the data obtained from at least five animals.

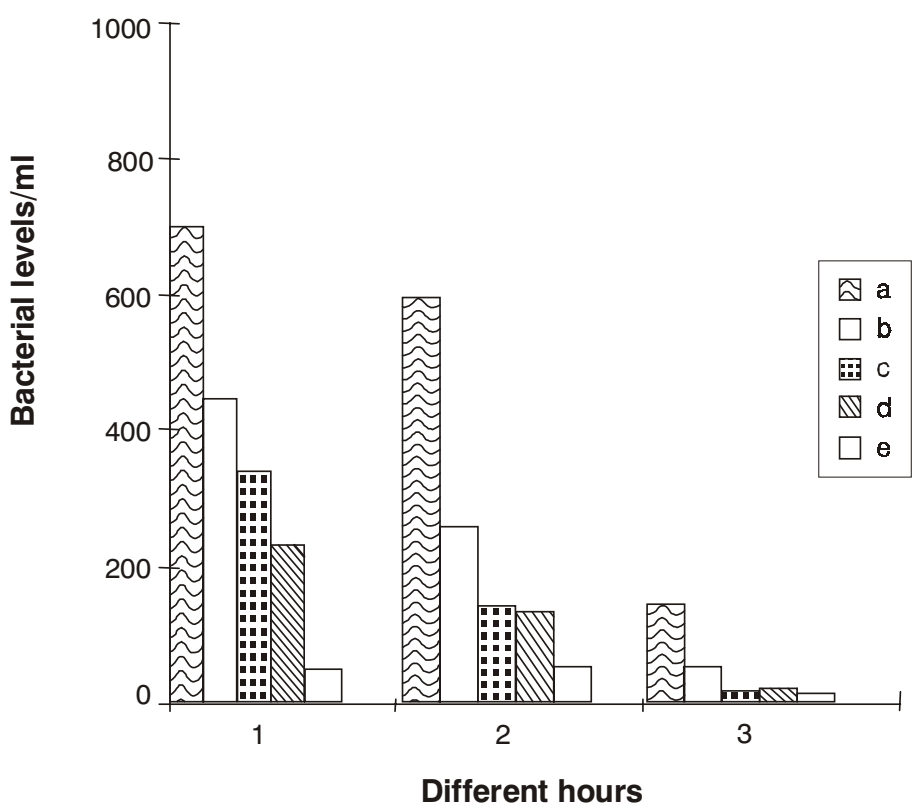

www.bjid.com.br 
Figure 3. Dot-plots of indirect immunofluorescence-activated cell sorter analysis of Neisseria meningitidis B:4:P1.9 (homologous strain). 1: the bacteria were incubated with the 8C7Br1 MAb (50kDa) diluted 1:1,000; 2: MAb 5F81A4 (P1.9) diluted 1:2,000; 3: MAb 1C31B8 Br4 immunotype (L8) diluted 1:2,000; 4: MAb 1B81C3Br5 immunotype (L1) diluted 1:1,000; 5: unrelated monoclonal antibody. Quadrant boundaries were constructed on the basis of the controls.

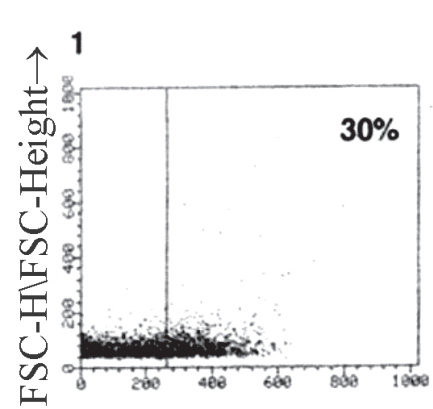

FL1-H\FL1Height $_{\mathbf{4}}$

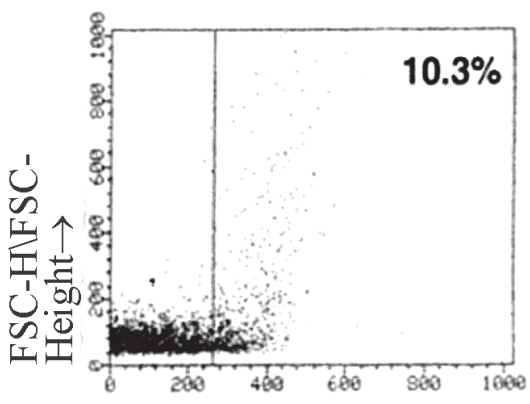

FL1-H\FL1-

Height $\rightarrow$

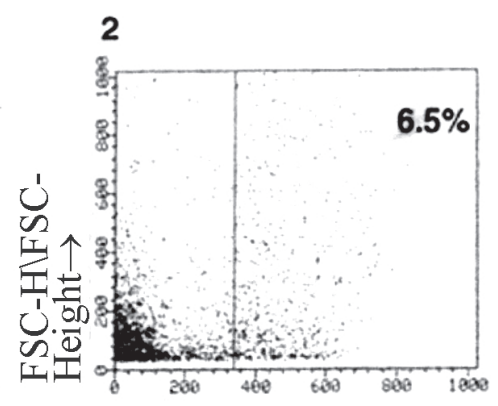

FL1-HJFL1-

Height $\rightarrow$

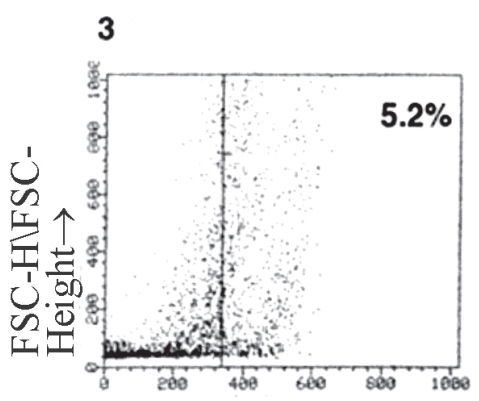

FL1-H\FL1-Height $\rightarrow$

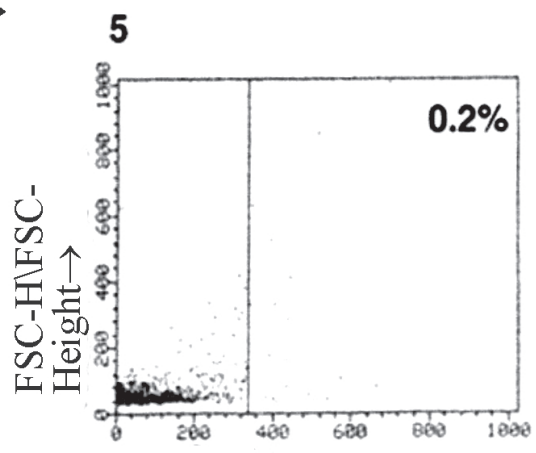

FL1-H\FL1-Height $\rightarrow$ 
The mice demonstrated uniform and high susceptibility to virulent $N$. meningitidis strain 368/88 (B:4:P1.9), developing progressive bacteremia. Mouse inoculations were made with meningococci scraped from plates after approximately $20 \mathrm{~h}$ culture, suspended in PBS to a concentration of $4 \times 10^{3}$ bacteria $/ \mathrm{mL}$. All inoculations were completed within $15 \mathrm{~min}$ after preparing the suspensions. Based on viable inocula counts before and after injection into the animals, this time lapse did not reduce viability. Female BALB/c mice (C5-sufficient) were obtained from the Adolfo Lutz Institute. Mice were inoculated with heat-inactivated mouse MAb ascites fluid via intravenous (i.v) injection. Five mice were inoculated with each MAb concentration (1:2,000, $1: 4,000,1: 8,000$ and $1: 16,000$ dilutions of the $\operatorname{IgG} 2 \mathrm{a}$ isotype in $0.25 \mathrm{~mL}$ ). The bacteria $\mathrm{B}: 4: \mathrm{P} 1.9$ (homologous strain) were administered via intraperitoneal (i.p) injection about 10 minutes later. Bacteremia was monitored by cutting the tip of the mouse's tail with a sharp scissors and collecting $10 \mathrm{~mL}$ of blood with an automatic pipette. Each blood sample was inoculated and spread with a sterile glass road onto TSB-supplemented agar with $1 \%$ heat-inactivated normal horse serum containing vancomycin, colistin, and nystatin (Sigma Chemical Co, Biotechnology, Piscataway, NJ) to inhibit the growth of other microorganisms. The bacterial colonies were counted after incubating at $37^{\circ} \mathrm{C}$ in the presence of $5 \% \mathrm{CO}_{2}$ for $18 \mathrm{~h}$. The rate of bacteremia for each group of animal was calculated as the arithmetic mean log 10 of the number of colony-forming units per milliliter of blood.

Determination of MAb 5F81A4 reactivity with the surface of $N$. meningitidis by flow cytometry

The ability of 5F81A4 MAb to bind to the surface of pathogenic strains of group B $N$. meningitidis was determined by means of flow cytometry, through indirect immunofluorescence of $N$. meningitidis strain $\mathrm{N} 368 / 88$. Whole cells in $0.02 \%$ sodium azide were washed and resuspended to an optical density of 1.0 at $650 \mathrm{~nm}$ in saline containing $1 \%(\mathrm{w} / \mathrm{v})$ bovine serum albumin (Sigma). Bacteria were then mixed in $100 \mathrm{~mL}$ with MAb (ascitic fluid) diluted in $200 \mathrm{~mL} \mathrm{S/BSA}$, and incubated at $37^{\circ} \mathrm{C}$ for $30 \mathrm{~min}$. Saline or "nonsense" MAbs specific for unrelated $\mathrm{IgG}$ were employed as negative controls. Antibody-exposed bacteria were washed twice with S/BSA and mixed with $200 \mathrm{~mL}$ of appropriately diluted FITC-labeled second antibody. The FITC-labeled probe was affinity-purified goat serum anti-mouse IgG. The bacteria were incubated with FITC-labeled antibodies for $30 \mathrm{~min}$ at $4^{\circ} \mathrm{C}$, washed twice with saline and resuspended in $1 \mathrm{~mL}$ of saline. The control consisted of bacteria incubated in $1 \%$ BSA in saline. All samples were analyzed in triplicate [15]. The positive controls were meningococcal MAbs specific for immunotypes L8 (1C31B8Br4) and L1 (1B81C3 Br5) [20]. Fluorescence emissions of 5000 stained bacteria from each sample were measured in a flow cytometer (FACScan; Becton Dickinson Immunocytochemistry Systems, Mountain View, CA). Forward-scatter threshold and live cell gates were optimized to exclude cell debris and large bacterial aggregates from the analyses. MAb binding was expressed as the percentage of cells with intensely higher fluorescence than those stained with negative control MAb.

\section{Results}

\section{Electrophoretic analysis of proteins}

Immunochemical characterization of $N$. meningitidis OMC was made by $13 \%$ SDS-PAGE (Figure 1:3a).

\section{Monoclonal characterization}

The immunoglobulin class and subclass of the MAb of cell line 5F81A4 was characterized by ELISA as being IgG (Ig2a, kappa light chain). This MAb was assessed with a Dot-Blot assay for specificity to reference strain P1.9 (M982) (Figure.1:2g) and to case strains N368/88, N398/92, N16/92, N17/92, N23/ 92, N35/92, N402/92, N403/92, and P1.9 (Figure.1:1a,b), using culture supernatant and ascites fluid, respectively. This MAb bound by immunoblot 
Table 2. Distribution of subtypes among Neisseria meningitidis analyzed

\begin{tabular}{lccrrrrrr}
\hline $\begin{array}{l}\text { Serogroups } \\
\text { (subtypes) }\end{array}$ & $\begin{array}{c}\text { B } \\
\text { Strains }\end{array}$ & \% & Strains & \% & Strains & \% & \multicolumn{2}{c}{ Total } \\
Strains & $\%$ \\
\hline P1.2 & 6 & 1.5 & 40 & 25.5 & 4 & 8.7 & 50 & 8.3 \\
P1.3 & 12 & 3.0 & 89 & 56.7 & 7 & 15.2 & 108 & 18.0 \\
P1.9 & 27 & 6.8 & 0 & 0 & 1 & 2.2 & 28 & 4.6 \\
P1.15 & 194 & 48.6 & 3 & 1.9 & 10 & 21.8 & 207 & 34.4 \\
P1.16 & 28 & 7.0 & 0 & 0.0 & 6 & 13.0 & 34 & 5.6 \\
NT & 132 & 33.1 & 25 & 15.9 & 18 & 39.1 & 175 & 23.1 \\
\hline Total & $\mathbf{3 9 9}$ & $\mathbf{1 0 0}$ & $\mathbf{1 5 7}$ & $\mathbf{1 0 0}$ & $\mathbf{4 6}$ & $\mathbf{1 0 0}$ & $\mathbf{6 0 2}$ & $\mathbf{1 0 0}$ \\
\hline
\end{tabular}

B: N. meningitidis serogroup B; C: N. meningitidis serogroup C; Others: W135, poli NG, Y serogroups; P1.2: N. meningitidis subtype 2; P1.3: N. meningitidis subtype 3; P19: N. meningitidis subtype 9; P1.15: N. meningitidis subtype 15; P1.16: N. meningitidis subtype 16; NT: N. meningitidis not serotyped with monoclonal antibodies used.

(Figure.1:4) to the class 1 protein, when $0.25 \%$ of Empigen BB detergent was added to restore the antibody binding activity to this class 1 subtype $\mathrm{N} 368 /$ 88 protein (Figure.1:4a), N16/92 (4c), N 23/92 (4e). Based on these results, the 5F81 A4 MAb was assumed to be subtype P1.9, and it was renamed as MAb 9. Another monoclonal antibody obtained in this fusion (1A11E10) with class $3(37 \mathrm{kDa})$ of $N$. meningitidis was used as a position marker on immunoblot [17] (Figure.1:4b,d,f), employing case strains N368/88, N16/92 and N23/92.

\section{Bactericidal activity}

The functional activity of MAb was measured by means of a bactericidal assay. Bactericidal activity of MAb 5F81A4 (P1.9) tested by a microbactericidal assay was $90 \%, 80 \%, 45 \%$ and $25 \%$, respectively, with B:4:P1.9 (homologous strain) at 1:50: 1:100: $1: 200$, and 1:500 ascites dilutions.

\section{Mouse bacteremia}

The protective effect of MAb 5F81A4 was assessed in mice. The rate of bacteremia was greatly reduced after $1 \mathrm{~h}$ treatment. Passive administration of MAb
5F81A4 to BALB/c mice significantly reduced bacteremia in a concentration-dependent manner (Figure 2).

\section{Flow cytometry analysis}

The ability of the 5F81A4 MAb to bind to $46 \mathrm{kDa}$ protein on the surface ofthe pathogenic $N$. meningitidis group B strain was also determined by indirect immunofluorescence assay and was analyzed by flow cytometry (Figure 3). The B:4:P1.9 strain of $N$. meningitidis was used.

\section{Serotype distribution}

The distribution of epitope 9 was estimated by screening 602 Brazilian N. meningitidis strains isolated from meningococcal disease cases during 1992. The new monoclonal antibody specifically recognized $N$. meningitidis class 1 of the P1.9 subtype epitope of reference strain M982 of N. meningitidis (Figure.1:2). Table 2 gives the extent of occurrence of these $N$. meningitidis B subtypes in 1992. Subtype P1.9 appears to be related to sorogrup B sorotype 4, contributing $6.8 \%$ of the subtype serogroup B strains in Brazil. The use of MAb did not decrease the 
Table 3. Reactivity of P1.9 monoclonal antibody with several Neisseria meningitidis B strains NT from different Brazilian states (Bahia, Ceará, Espírito Santo, Pernambuco, Paraná, Rio de Janeiro, Santa Catarina, São Paulo)

\begin{tabular}{lrcc}
\hline Brazilian states & N & P1.9 & \% \\
\hline Bahia & 44 & 3 & 0.5 \\
Ceará & 3 & 1 & 0.2 \\
Espírito Santo & 63 & 4 & 0.7 \\
Pernambuco & 59 & 6 & 1.0 \\
Paraná & 37 & 2 & 0.3 \\
Rio de Janeiro & 88 & 1 & 0.2 \\
Santa Catarina & 36 & 2 & 0.3 \\
São Paulo & 264 & 9 & 1.4 \\
\hline Total & $\mathbf{5 9 4}$ & $\mathbf{2 8}$ & $\mathbf{4 . 6}$ \\
\hline
\end{tabular}

Table 4. Distribution of P1.9 subtype among Neisseria meningitidis serotypes of serogroup B analyzed

\begin{tabular}{lrrrrrr}
\hline Serotypes & $2 \mathrm{~b}$ & 4 & 8 & 15 & NT & Total \\
Strains & 2 & 115 & 12 & 3 & 25 & 157 \\
MAb P1.9 & 0 & 21 & 1 & 1 & 4 & 27 \\
$\%$ & 0 & 18 & 8 & 33 & 16 & 17 \\
\hline
\end{tabular}

percentage of nontypable serogroup C strains. However, there was a decrease in nontypable strains to serogroup B, $18.3 \%$. The distribution of the P1.9 epitope in strains isolated from various Brazilian states was determined (Table 3). Through the use of a set of MAbs for the serotypes and subtypes, it was observed that subtype P1.9 is related to serotype B:4 (Table 4 ).

\section{Discussion}

The most appropriate screening methods and subtyping analysis are required for an adequate investigation. A panel of well-characterized subtypespecific MAbs should be selected, in order to identify most strains. This epidemiological screening method has proven to be effective in assessing outbreaks during the last 15 years.
Typing of $N$. meningitidis includes determination of group, serotype, and subtype by either whole-cell ELISA or with dot blot assays, using MAbs. The subtype specificity of MAb is defined by its reactivity, by immunoblot analysis, to the approximately $46 \mathrm{kDa}$ OMP (PorA) of the immunizing strain. Subtyping MAbs usually bind to one of two VRs of PorA, and many of these epitopes are known. In recent years, several mutants of subtypeable strains carrying point mutations and deletions in VR1 and VR2 that fail to bind to subtype-specific MAbs have been isolated [18]. These identified subtype variants have been designated as such by the addition of a lowercase letter to the subtype name.

The PorA, or N. meningitidis class 1 outer membrane porin protein, has been used as the subtyping antigen for the characterization of meningococci. Monomeric PorA is a transmembrane protein with eight 
outer loops, among which the first and the fourth loop contain the hypervariable regions, called variable region 1 (VR1)and VR2, respectively [19]. These two regions define the dual PorA subtype, designated P1. x,y, where "P1" stands forthe class 1 protein and " $\mathrm{x}$ " and " $\mathrm{y}$ " stand for numbers denoting the VR1 and VR2 domains, respectively. The two subtype regions of PorA are generally determined by an (ELISA) [20] or a blotting assay, with reference MAbs directed against epitopes in VR1 or VR2; consequently, each PorA can bind to two different subtype-specific MAbs. In addition, variations in VR1 and VR2 can be analyzed by sequencing porA genes [19-21].

The value of producing monoclonal antibodies to a nontypable meningococcal strain is probably related to the frequency with which the strains of this antigenic phenotype are isolated from the population. If a nontypable group B strain is representative of a significant percentage of case isolates, it may be desirable to use it in vaccine production or as a target strain in bactericidal assays. Nongroupable $N$. meningitidis can constitute one third or more of meningococcal isolates recovered from the nasopharynx of human carriers [22].

The profile of outer membrane protein bands on SDS polyacrylamide gels can be used to survey nontypable strains and as presumptive data about whether a given strain is representative (presenting the same serotype and subtype) of a significant percentage of all nontypable strains.

MAbs prepared against frequent nontypable strains can be used for a number of purposes: (a) for serotyping, serosubtyping, and immunotyping meningococcal isolates; (b) to identify additional protective antigens; (c) to monitor the stability of antigenic expression of the strain used in bactericidal assays, or for vaccine production; (d) to determine the degree of antigenic variation that occurs in a particular antigen; (e) to select positive clones for the expression of a specific antigen in gene cloning experiments; (f) to identify new strains with epidemic potential, or a change in the antigenic phenotype of an epidemic strain; and (g) to select strains to include in group B vaccines, or for evaluating vaccine potency by means of bacterial assays [23,24].
When fusions are performed, the nature of the immunization antigen, and the technique used for screening antibody-producing clones, will determine which monoclonal antibodies will be the most suitable. With careful planning, a variety of useful antibodies may be obtained from a single fusion $[11,13]$.

Some of the applications of monoclonal antibodies have not been specifically related to nontypable strains, but rather to MAbs in general. Monoclonal antibodies have provided the most accurate and detailed characterization of meningococcal isolates when compared with previously used tools. This capability can lead to new insights into the epidemiology and the pathogenesis of meningococcal disease. For instance, it was previously thought that there was no relationship between nasopharyngeal meningococci and the incidence of disease. By using monoclonal antibodies to identify epidemic strains on the basis of serotype and subtype, a high correlation between carriage of an epidemic strain and the incidence of disease has been shown.

MAb 5F81A4 appeared to bind to an epitope in a conformational-dependent manner. After denaturation in SDS-PAGE, MAb 5F81Br4 bound only to the class 1 antigen of $N$. meningitidis $\mathrm{B}(\mathrm{P} 1.9)$.

At the appropriate concentrations, the MAb that we have described has effectively defined most of the strains with the P1.9 subtype in screening procedures, but it has failed to detect at least one variant strain. It would be impractical to include multiple antibodies for each subtype variant that has been identified, since epidemiological screening would then require about 15 MAbs. The investigator must be aware that some subtype variants will not be detected.

MAbs form the basis of meningococci typing for diagnostic and epidemiological purposes. Recently, an increased number of strains have been isolated that fail to react with the current set of Mabs; therefore new typing methods have been sought [25]. One way to assess the diversity of meningococcal antigens is to determine the nucleotide sequence of the genes that encode them. The most studied gene is por $A$, encoding the class 1 outer membrane protein (Por A), which is a target for serosubtyping MAbs. A new scheme for the 
designation of subtypes based on their amino acid sequences has been proposed [26], and this information, combined with a knowledge of MAbs structure may ultimately lead to engineering reagents with desired specificities. We used the P1.9 subytype to illustrate the particular effect on the development of comprehensive new reagents for defining meningococcal subtypes, to be used as proteins for vaccine preparation in Brazil [27]. The composition of various group B OMP vaccines, and clinical trials using vaccines against $N$. meningitidis $B$ were recently reviewed [1].

\section{Acknowledgements}

We thank Dr Mirthes Ueda of the Instituto Adolfo Lutz (IAL) for constructive reading of the manuscript, Ana Paula Lemos, Bacteriology Departament, (IAL) for supplying the reference strains, Carmen Aparecida de Freitas, Serology Department (IAL) for technical support in FACS results interpretation, and Drs. WD Zollinger of the Walter Reed Army Institute of Research, Maryland and JT Poolman of the Rijsinstituut voor Volksgezondheit en Milieuhygiene, Bilthoven for supplying the monoclonals used in serotyping. Funding came from FAPESP Grants 99/00638-6 and 99/ 00557-6.

\section{References}

1. Morley S.L., Pollard A.J. Vaccine prevention of meningococcal disease, coming soon? Vaccine 2002;20:666-87.

2. Sacchi C.T., Lemos A.P., Popovic T., et al. Serosubtypes and PorA types of Neisseria meningitidis serogroup B isolated in Brazil during 1997-1998: Overview and implications for vaccine development. J Clin Microbiol 2001;39:2897-903.

3. Caugant D.A. Population genetics and molecular epidemiology of Neisseria meningitidis. APMIS 1998; $106: 505-25$.

4. Frasch C.E., Zollinger W.D., Poolman J.T. Serotype antigens of Neisseria meningitidis and a proposed scheme for designation of serotypes. Rev Infect Dis 1985; 7:504-10.
5. Scholten R.J., Kuipers B., Valkenburg H.A., Dankert J., Zollinger W.D., Poolman J.T. Lipo-oligosaccharide immunotyping of Neisseria meningitidis by a wholecell ELISA with monoclonal antibodies. J Med Microbiol 1994;41:236-43.

6. Tzeng Y.L., Stephens D.S. Epidemiology and pathogenesis of Neisseria meningitidis. Microbes Infect 2000;6: 687700.

7. Abdillahi H., Poolman J.T. Neisseria meningitidis group B serosubtyping using monoclonal antibodies in wholecell ELISA. Microbiol Pathol 1988;4:27-32.

8. Poolman J.T., Abdillahi H. Outer membrane protein serosubtyping of Neisseria meningitidis. Eur J Clin Microbiol Infect Dis 1988; 7:291-2.

9. De Gaspari E.N., Ribeiro-Filho A.A, Zollinger W.D. Importance of the use of subtype P1.9 monoclonal antibody for the serotyping of Neisseria meningitidis serogroup B strains in Brazil pp. 348. In Evans, JS, Yost, SE, Maiden, MCJ, IM Feavers (eds), Abstracts of the Ninth International Pathogenic Neisseria Conference, The Guildhall Winchester, England, 1994.

10. Wedege E., Caugant D.A., Musacchio A., et al. Redesignation of a purported P1.15 subtypespecific meningococcal monoclonal antibody as a P1.19-specific reagent. Clin Diagn Lab Immunol 1999;6:639-42.

11. De Gaspari E.N. Production and characterization of a new monoclonal antibody against Neisseria meningitidis: study of the cross-reactivity with different bacterial genera. Hybridoma 2000; 6:445-53.

12. Lowry O.H., Rosebrough J.N., Farr L., Randall R.J. Protein measurement with the folin phenol reagents. J Biol Chem 1951; $193: 265-75$.

13. De Gaspari E.N., Zollinger W.D. Expression of class 5 antigens by meningococcal strains obtained from patients in Brazil and evaluation of two new monoclonal antibodies. Braz J Infect Dis 2001;3:143-53.

14. Maslanka S.E., Gheesling L.L., Libutti D.E., et al. Standardization and a multilaboratory comparison of Neisseria meningitidis serogroup A and C serum bactericidal assays. The Multilaboratory Study Group. Clin Diagn Lab Immuno 1977;14 :156-67.

15. De Oliveira L.M.C., De Gaspari E.N. Study of the new cross reactive monoclonal antibody against Neisseria meningitidis using flow cytometry analysis. Analyt celular Pathol 1997; 14 :191.

16. Thomaz Belo E.F. Expressão Antigênica de LPS das Cepas Meningocóccicas Prevalentes no Brasil, Produção de Anticorpos Monoclonais como Subsídios para Estudos Epidemiológicos. Ph.D. Thesis, 2002 Faculdade de Ciências Farmacêuticas Universidade de São Paulo, São Paulo, 95 pp. 
17. De Gaspari E.N., Sanchez C.S.R., Zollinger W.D. Monoclonal antibodies to new serotypes and subtypes of Neisseria meningitidis and their use in serotyping . An Acad Bras de Ciênc 1995;96:121-9.

18. Wedege E., Dalseg R., Caugant D.A., et al. Expression of an inaccessible P1.7 subtype epitope on meningococcal class 1 proteins. J Med Microbiol 1993;38:23-8.

19. van der Ley P., Heckels J.E., Virji M., et al. Topology of outer membrane porins in pathogenic Neisseria spp. Infect Immun 1991;59:2963-71.

20. Zollinger W.D., Moran E.E., Connelly H., et al. Monoclonal antibodies to serotype 2 and serotype 15 outer membrane proteins of Neisseria meningitidis and their use in serotyping. Infect Immun 1984; 46:260-6.

21. Saunders N.B., Shoemaker D.R., Brandt B.L., Zollinger W.D. Confirmation of suspicious cases of meningococcal meningitis by PCR and enzymelinked immunosorbent assay. J Clin Microbiol 1997;35:3215-9.

22. Feavers I.M., Fox A.J., Gray S., et al. Antigenic diversity of meningococcal outer membrane protein PorA has implications for epidemiological analysis and vaccine design. Clin Diagn Lab Immunol 1996;3:444-50.

23. Saukkonen K., Leinonen M., Kayhty H., Abdillahi H., Poolman J.T. Monoclonal antibodies to the rough lipopolysaccharide of Neisseria meningitidis protect infant rats from meningococcal infection. J Infect Dis 1988; $158: 209-12$.

24. Suker J., Feavers I.M., Maiden M.C.J. Monoclonal antibody recognition of members of the meningococcal P1.10 variable region family: implications for serological typing and vaccine design. Microbiology 1996;142: 63-9.

25. Saunders N.B., Brandt B.L., Warren R.L., et al. Immunological and molecular characterization of three variant subtype P1.14 strains of Neisseria meningitidis. Infect Immun 1998;66:3218-22.

26. De Gaspari E.N., Ribeiro-Filho A.A., Zollinger W.D. The use of filter paper monoclonal antibodies in a Dot-blot test for typing Neisseria meningitidis B. Braz J Med Biol Res 1994;27:2889-93.

27. Coutinho L.M.C.C. Uso de Anticorpos Monoclonais na Seleção de Antígenos Lipopolissácarides (LPS) da Cepa Epidêmica B:4:P1.15 de Neisseria meningitidis B: Imunização Nasal. Thesis 2002. Faculdade de Ciências Farmacêuticas Universidade de São Paulo, São Paulo, $135 \mathrm{pp}$. 